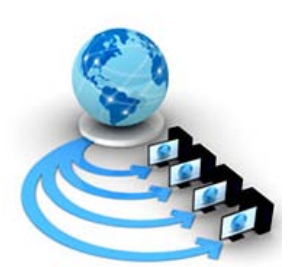

Volume 11, No. 5, September-October 2020

International Journal of Advanced Research in Computer Science

RESEARCH PAPER

Available Online at www.ijarcs.info

\title{
AN ANALYTICAL STUDY ON DIRECTIONS AND PROFILE MATCHING FOR CARPOOL SYSTEM
}

\author{
Jyoti Ranjan Mohanty \\ Research Scholar \\ Dept. of Computer Application \\ SSSUTMS, Sehore \\ M.P., India
}

\author{
Dr. Jitendra Sheetlani \\ Associate Professor \\ Dept. of Computer Application \\ SSSUTMS, Sehore \\ M.P., India
}

\author{
Dr. Rasmi Ranjan Patra \\ Asst. Professor \\ Dept. of CSA \\ OUAT, Bhubaneswar \\ Odisha, India
}

\begin{abstract}
These days, numbers of citizens are exploring different approaches to make better effective use of existing resources. In country like India, there are nearly about one to two people for every car and the number of person in an average car is nearly five. As a result of this, it is clearly understandable that the car driving has great potential for competence in this regard, on the basis of sharing of personal vehicles. Plenty of time and energy is saved by Carpooling, from a public and environmental point of view, but most importantly it reduces air pollution. Carpooling can share the location of each car between people with similar path or route. Carpooling evolved as an economical and anxiety-free system for distribution. In this analytical study paper, presentation of information is made about an overview of computer-based platforms that improve sustainability. In particular, this discussion will help car users choose the basis of transportation solutions for their natural footprint based on their needs, preferences and location. The success rate of this automotive system is based on the relative routes that directly connect traditional points and destinations to the most involved passengers and increase the integer of association from single to double, requiring change in two successive passengers. This analytical study paper reviews from the artistic nature of the modern carpooling method. It identifies the most important challenges in adopting modern carpooling system and the anticipated results to the same identified problems.
\end{abstract}

Keyword: Carpooling, Genetic algorithm, CLACSOON, AICS, HTTP, Mobile Client

\section{INTRODUCTION}

In present scenario traffic jam is considered to be the huge problem in transportation system of metro cities. This destroys the life style, which leads to far-reaching social, economic and environmental impacts. The solution to the traffic jam problem has top most propaganda in different metro cities. Different analysis has been performed for increasing the efficiency in modern traffic management system. Various transportation models along with their solution systems have been anticipated for improving management in modern transportation systems, which includes the combination of research work and improvised decision support systems based on knowledge in order to signal control optimization. Now, carpooling is considered to be one of the finest solution for challenging congestion in traffic.

Carpooling also referred to Ridesharing or Carsharing, is stated as car travel segmentation, in which a passenger makes his own journey in one or more than one car, which reduces fuel cost, toll fee, etc. However, in particular, one from a social and environmental perspective, reducing air pollution. Carpooling is the sharing of personal car seats between passengers with a similar trajectory. Though there are number of specific software are available which help in the carpooling exercises, any one of them are not equally applicable for finding out the people with related trajectories and their profiles. This assessment is depended on the significance of society, economic and environmental pros for implementing carpooling, as it reveals consumer motivation and helps build a common platform.

This research paper is organized as per the following. For illustration of carpooling system with its merits, Section 3 elaborately describes carpooling system. Give a brief overview of Section 4 and various implementations of carpooling systems about carpooling system models and functions; Section 5 gives various issues related to carpooling.

\section{RELATED WORK}

As per the earlier analysis, research over carpooling has turn into an important exciting area in early research fields. Several resolutions are found in which various alternatives to the existing problem have been suggested. A wide-ranging analysis of carpooling systems was presented by Agatz, Erera, Sowelsberg and Wang (2012). Various intention-based function are utilized within relevant context of carpooling systems (Nazmi, Ray, \& Rashidi, 2017). Some studies aim to reduce both the network's car and travel costs (Guo, Gonclaves, \& H, 2013 and Huang et al., 2016; Yan \& Chen, 2011). A number of focus over the infringement costs of 
delaying carpooling services (Guo, Gonclave, \& Hsu, 2013. Yan; Chen, \& Chang, 2014).

Agatz, Erera, Sawelsburg and Wang (2011) established an optimized approach to carpooling difficulty, to reduce the cost of both drivers as well as passengers. Yan and Chen (2011) applied time-space network flow methods through many type of vehicles and individual type to the carpooling problem. He used the Lagregian relaxation method to resolve the difficulty. Brugglieri, Siccarelli, Colarni, and Lu_e(2011) founded carpooling system meant for university staff, teachers along with scholars. Pelzer et al. (2015) reducing detergents by leaving extra passengers in the carpooling process. He utilized a heuristic agent based method to resolve various issues. Chou, Xiao and Huang (2016) represented a stochastic setbased particle swarm optimization (PSO) algorithm to give a reasonable matching of ride due to the carpooling difficulty.

As per past analysis in carpooling systems, past analysis presumed that there were full-time drivers who would take each and every passenger, for which the drivers would not be liable to the request for transportation. The participated car does not belong to the members of carpooling system. In addition to that, most of the past reviews make an assumption that cars and drivers are well know to each other in advance. While in some other studies, there is no consideration about the problem of car and drivers as input.

In these studies, the model is asked to identify whether a particular subcommittee of riders can afford the car to participate in carpooling job, and to require all members of that subcommittee to work in driver form and pickup the others. Therefore, the primary cost is to select drivers and hand them over to other passengers, thereby reducing the overall charge. Though the structural complexity of the difficultness grows by this, it makes this carpool model more adaptable to the real-world situations. Moreover, it is clearly acceptable from the literature review that more attention has been given to the management of carpooling systems through heuristic and meta-heuristic methods, with respect to the solution methodology.

\section{CARPOOLING}

Carpooling comes with car travel regulations as a result of which most passengers can make their journey by car. This makes easier for travel or irregular long drive journey. Carpooling propose many advantages, which could be economic, environmental, society which reduces the number of cars moving on roads.

Everyone knows that carpools can reduce costs in a simple way that determines their expenditures when riding jointly. In spite of this car sharing also diminishes time required to travel and also the costs associated with parking.

From environmental point of view, the analysis is approached to reduce greenhouse gas emissions and reduce traffic congestion. Car ownership is argued to lead to air pollution and alteration in environment. Using of carpooling by the passengers instead of using their personal car, reduces Carbon Dioxide (CO2) emissions and contributes to environmental protection.

Social interaction among the unknown passengers is another benefit of this method. Strangers have to collect new people using carpooling when they are interested to ride a person's car. As per the prior discussion, car pooling can also be used by friends, married couples and rich association. Along with this, sharing of ideas and knowledge can be done among the carpoolers.

The main purpose of carpooling is to exchange of ideas which is beneficial to each and every individual of the society.

\section{CARPOOLING MODEL}

There are various carpooling system models such as CarpoolWorld and Share Your Ride. In CarpoolWorld System, users have got facilities to search as per their necessities and find appropriate identical outputs. This carpool system does not perform over Geographic Information System (GIS). Therefore this system does not impart location of riders and cars in real-time. Share Your Ride model utilizes a geographical map-based communications to recognize requirements from users and facilitate digital GIS services for matching requests. It does not use the Global Positioning System (GPS) handheld device, so it does not supply immediate facilities for retrieving data about passenger's present position. This particular section makes discussion about two different carpooling models which are applicable to perform carpooling function on various results examined for the carpooling process.

\section{A. The CLACSOON System}

This system is intended to provide real-time carpooling services to the urban area. The basics of people who do not need planning for mobilization in the city cannot be established in advance. This system is intended for use by people with portability, therefore accessing the same system should determine through portable appliances. The Architectural Design of this system recognizes such capability and looking upon the operating system, the outer layer is planned for portable appliances. On the inner layer, the cloud is utilized to facilitate a greater number of expected networks and then better access and capability.

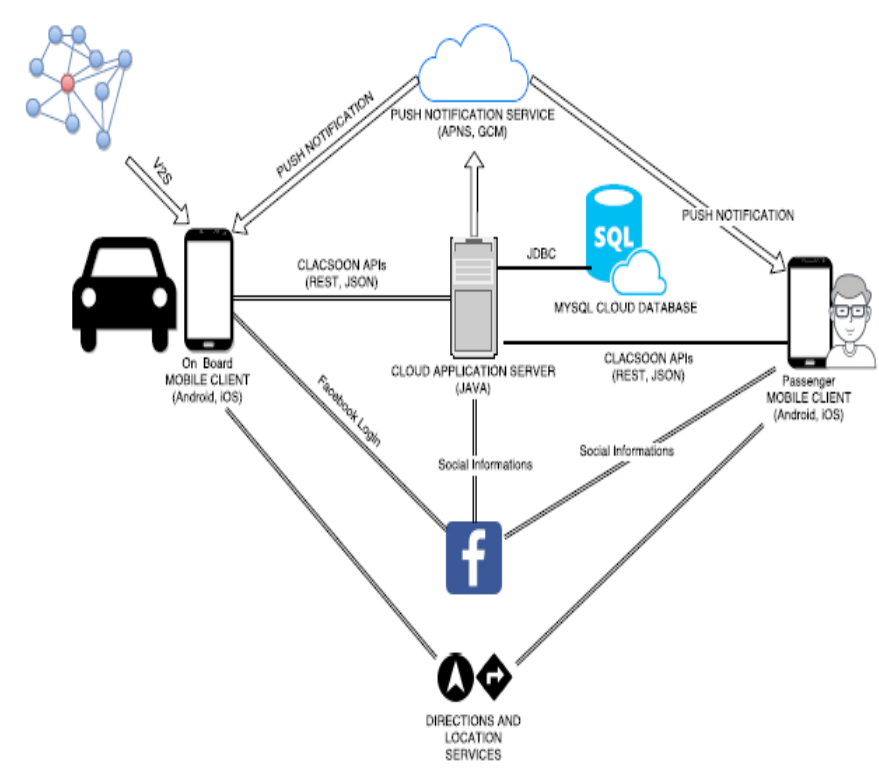

Figure 1. The CLACSOON system

The CLACSOON's route matching algorithm and the model of ride-sharing treat the algorithm as a fractional ridesharing mode, meaning that a rider takes into account the possibility of the driver reaching his / her path, making it possible for the driver. Ho takes the diversion. In addition, the algorithm applies a technique to understand the driver's location in the urban context, allowing the driver to share the car after the journey begins. 


\section{B. AICS (Advanced Intelligent Carpool System)}

AICS is a kind of service model which is based on cloudcomputing for providing service in carpool. AICS is designed through combination of web based applications. It consists of two basic components: the Mobile Client (MC) module and the Cloud Global Carpool Services (CGCS) module. Here exchange is made in between the MC module and the CGCS module by utilizing the Web HTTP protocol via the mobile module. Request may be sent by Individuals for carpooling and ultimately receive the same results anytime and anywhere through the Mobile Client (MC) component. Cloud Global Carpool Service Module has obtained requests made from MC Component to fulfill car component demands. The CGCS module has a wide GIS.



Figure 2. Advanced Intelligent Carpool System

A Genetic algorithm based carpool way along with a matching algorithm drastically reduces the required time for matching between huge volumes of people.

\section{ISSUES RELATED TO CARPOOLING}

Carpooling service has a few drawbacks. Complete freedom is not given to the drivers because the increase in people in the car increases more plans to remember. Many security issues in this method are unknown to each other. Consider the issues:

- Carpooling with a stranger raises safety concerns and problems regarding travelling in a car with stranger passengers, though the chance of offense is negligible. The most commonly adapted technique to solve the above type of problems is to use a reputed system which identifies customers causing problems and increases the confidence level of responsible customers.

- Suppleness is another important factor as it is too difficult to fine-tune the lag of the path or change the pattern already set. The first two reasons people do not carpool are location and time frame and ease of travel.
- Access is another issue. The system requires a lot of carpooling to work, the probability of a match for such a journey is very low and it requires more active people.

- $\quad$ Ride sharing allows anyone to become a taxi driver and legal hurdles are a concern as such service becomes very frequent.

\section{CONCLUSION AND FUTURE WORK}

Carpooling provides private transport system which helps to solve important common difficulties in the municipal area, for example environmental contamination, traffic jamming and more. The problems related to carpooling involve declaring and sharing methods among the passenger subcommittee that covers each car. Drivers must follow, which means the partnership is increased and the overall cost of transportation are decreased. The basic purpose of such study is for analyzing some models related to carpooling system that make a flexible and comfortable journey for both the riders and driver.

In this analytical study paper, our focus is on basically converse the intelligent means of carpooling that facilitates a base where intended users can quickly explore and get carpool options anywhere; our key attempt is to solve whole pattern of carpooling. It gives a base for drivers and riders to effortlessly locate carpools anywhere. CLACSOON's route matching algorithm and genetic algorithm are applied to find out route similarities.

This work can be expanded to implement multi-hop car sharing in the future (i.e. travel with many drivers). Different early trip time assessment methods can be further considered to improve the estimation of ride travel time.

\section{REFERENCES}

[1]. Agatz, N., Erera, A., Savelsbergh, M., \& Wang, X. (2012).Optimization for dynamic ride-sharing: A review. European Journal of Operational Research, 223, 295-303.doi:10.1016/j.ejor.2012.05.028.

[2]. Agatz, N., Erera, A. L., Savelsbergh, M. W. P., \& Wang, X.(2011). Dynamic ride-sharing: A simulation study in metro Atlanta. Procedia-Social and Behavioral Sciences, 17 , 532-550. doi:10.1016/j.sbspro.2011.04.530.

[3]. Bruglieri, M., Ciccarelli, D., Colorni, A., \&Lu_e, A. (2011).PoliUniPool: A carpooling system for universities. Procedia-Social and Behavioral Sciences, 20, 558-567.doi:10.1016/j.sbspro.2011.08.062Calvo, R., Wolfler, F., de Luigi,

[4]. Chou, S.-K., Jiau, M.-K., \& Huang, S.-C. (2016). Stochastic set-based particle swarm optimization based on local exploration for solving the carpool service problem. IEEE Transactions on Cybernetics, 46, 17711783. doi:10.1109/TCYB.2016.2522471.

[5]. Guo, Y., Goncalves, G., \& Hsu, T. (2011). A guided genetic algorithm for solving the long-term car-pooling problem. Paper presented at the computational intelligence in production and logistics systems (CIPLS), 2011. IEEE Workshop, Paris, France. 
[6]. Guo, Y., Goncalves, G., \& Hsu, T. (2012). A clustering ant colony algorithm for the long-term car-pooling problem. International Journal of Swarm Intelligence Research(IJSIR), 3, 39-62. doi:10.4018/jsir.2012040103.

[7]. Guo, Y., Goncalves, G., \& Hsu, T. (2013a). RETRACTEDARTICLE: A multi-agent based selfadaptive genetic algorithm for the long-term carpooling problem. Journal of Mathematical Modeling and Algorithms in Operations Research, 12(1)-45-66. doi:10.1007/s10852-012-9175-7.

[8]. Guo, Y., Goncalves, G., \& Hsu, T. (2013b). A multi destination daily carpooling problem and an ant colony based resolution method. RAIRO - Operations Research,47, 399-428. doi:10.1051/ro/2013049.

[9]. Najmi, A., Rey, D., \&Rashidi, T. H. (2017). Novel dynamic formulations for real-time ride-sharing systems. Transportation Research Part E: Logistics and Transportation Review, 108, 122-140.

[10]. Pelzer, D., Xiao, J., Zehe, D., Lees, M. H., Knoll, A. C., \&Aydt, H. (2015). A partition-based match making algorithm for dynamic ridesharing. IEEE Transactions on Intelligent Transportation Systems, 16, 2587-2598.

[11]. Yan, S., \& Chen, C.-Y. (2011). An optimization model and a solution algorithm for the many-to-many car pooling problem. Annals of Operations Research, 191, 37-71.doi:10.1007/s10479-011-0948-6.

[12]. Yan, S., Chen, C.-Y., \& Chang, S.-C. (2014). A car pooling model and solution method with stochastic vehicle travel times. IEEE Transactions on Intelligent Transportation Systems, 15, 47-61. doi:10.1109/TITS.2013.2272085. 